\title{
STUDY OF FLOW IN AIR-INTAKE SYSTEM FOR A SINGLE-CYLINDER GO-KART ENGINE
}

\author{
S. A. Sulaiman, S. H. M. Murad, I. Ibrahim and Z. A. Abdul Karim \\ Department of Mechanical Engineering, Universiti Teknologi PETRONAS \\ 31750 Tronoh, Perak, Malaysia \\ Phone: +605-3687013, Fax: +605-3656461 \\ Email: shaharin@petronas.com.my
}

\begin{abstract}
Intake-air manifolds have a major effect on a vehicle's engine performance and emission of noise and pollutants. Differences in engine outputs and applications require different designs of intake-air manifolds in order to achieve the best volumetric efficiency and thus the best engine performance. In the present work, the flow characteristics of air flowing in various designs of air-intake manifold of a 200-cc fourstroke Go-Kart engine are studied. The study is done by three dimensional simulations of the flow of air within six designs of air-intake manifold into the combustion chamber by using commercial CFD software, Fluent version 6.2. The simulation results are validated by an experimental study performed using a flow bench. The study reveals that the variations in the geometry of the air-intake system can result in a difference of up to $20 \%$ in the mass flow rate of air entering the combustion chamber.
\end{abstract}

Keywords: Air Flow, Go-Kart, Air-Intake

\section{INTRODUCTION}

In Go-Kart racing, it is common that the race format is a sprint race, which takes place on dedicated kart circuits resembling small road courses, with left and right turns. The lengths of tracks for racing range from 400 to 1600 meters (James, 2004). During sprinting, the engine is ramped quickly at various speeds due to the twisty course tracks. It is very seldom that an engine could go at high speed for a long time. The Go-Kart constantly needs to apply brakes and re-accelerate when taking corners. Thus, it is important that the engine can deliver a high torque at even low speeds; this can be achieved with modification of the air intake manifold. In a single cylinder engine, the maximum output performance achievable is related to the amount of air that is trapped in the combustion chamber. This is defined by the volumetric efficiency, $\eta_{v}$, which is the ratio of the mass of air trapped in the cylinder to that contained in the swept volume of the cylinder at inlet manifold density. If the volumetric efficiency could be increased significantly even at low speeds, the engine output would be expected to be higher.

It has long been realized that the design of air intake manifolds has a large effect on the performance of reciprocating engines. The unsteady nature of the induction means that the effect of the manifold on charging and discharging is dependent on the engine speed. The manifold must be designed to enable the engine to ingest air (Pulkrabek, 2004), and thus the inside diameter of the manifold must be able to accommodate the bulk air flow in order to avoid low volumetric efficiency. On the other hand, if the manifold flow path is too restrictive, the desired high air velocity and 
turbulence cannot be assured, and this will consequently affect its capability in carrying fuel droplets as well as in enhancing evaporation and air-fuel mixing (Winterbone and Pearson, 1999). In order to minimize flow resistance, the manifold should have no sharp bends and the interior wall surface should be smooth. Furthermore, the impedance of the manifold is a function of the frequency of the pulses entering it (Fontana et al., 2003), and thus it is possible to tune engine manifolds to give a particular power output characteristic as a function of speed.

Study of the effect of the geometry of the intake manifold was previously done using various designs, without changing the engine specifications, in a wide open throttle condition (Winterbone and Pearson, 1999). The intake manifold used was of a modular construction so that the primary pipe length, plenum volume and secondary pipe length could be varied. It was reported that the plenum volume could have a profound effect on the control at idling speed, which could be beneficial, although it reduced the engine's performance. The motion of fluid into the combustion chamber is important to speed up the evaporation of fuel, to enhance air-fuel mixing and to increase combustion speed and efficiency (Srinivasan, 2001). Due to the high velocities involved, the air flow within the engine system is turbulent, which causes the thermodynamic heat transfer rates within the engine to increase by an order of magnitude. As the engine speed increases, the flow rate increases, and consequently increases the swirl, squish and turbulence intensity (McLandress et al., 1996). This increases the real time rate of fuel evaporation, mixing of the fuel vapour and air and combustion. The high turbulence near the top-dead-center when ignition occurs is very desirable for combustion, as it breaks up and spreads the flame front many times faster.

The objective of the present work is to study the flow characteristics of air flowing in various designs of air-intake manifold used for a single-cylinder Go-Kart engine. The study is conducted by experiments and also by using computational fluid dynamics (CFD) simulation software, Fluent. The effects of different air intake geometry or configurations are studied. The experiments, which are conducted by using a commercial flow bench, are also used to validate the CFD simulation results. The parameters of interest are the flow rate and the flow coefficient of air entering the combustion chamber.

\section{EXPERIMENTAL SETUP}

The air-intake manifold was meant to serve a single cylinder 4-stroke spark ignition engine of an undisclosed manufacturer. The engine's displacement was $199 \mathrm{~cm}^{3}$ with a bore and stroke of $70 \mathrm{~mm}$ and $51.8 \mathrm{~mm}$ respectively. There were only two valves for the cylinder; each for the air intake and the exhaust. The intake valve diameter was $32 \mathrm{~mm}$. A challenge for the manufacturer would be to get the highest air flow rate entering through the single valve opening. In the present work, only the engine's cylinder head was used.

The flow bench equipment, SuperFlow SF-1020, was used to measure the characteristics of air entering the intake manifold and combustion chamber. Some of the experimental results using the flow bench would also be used to validate the results of the CFD simulations. The flow bench consisted of an open circuit ducting system that had an air pump at the downstream to induce air flow. The pressure within the ducting system could be varied by changing the speed of the air pump. The flow bench equipment setting is shown in Figure 1. The engine's cylinder head with complete valves assembly was attached to an acrylic chamber, which resembled the engine's 
cylinder, at the top of the bench. A dial gauge was mounted at the top of the intake valve to enable precision variation of the valve lifts. The intake manifold was attached to the cylinder head to seal the air from leakage. The measurement instrumentations for the system were linked to a data acquisition system. The specifications of the flow bench system are shown in Table 1. Detailed descriptions of the system were reported elsewhere (Ismail et al., 2008).

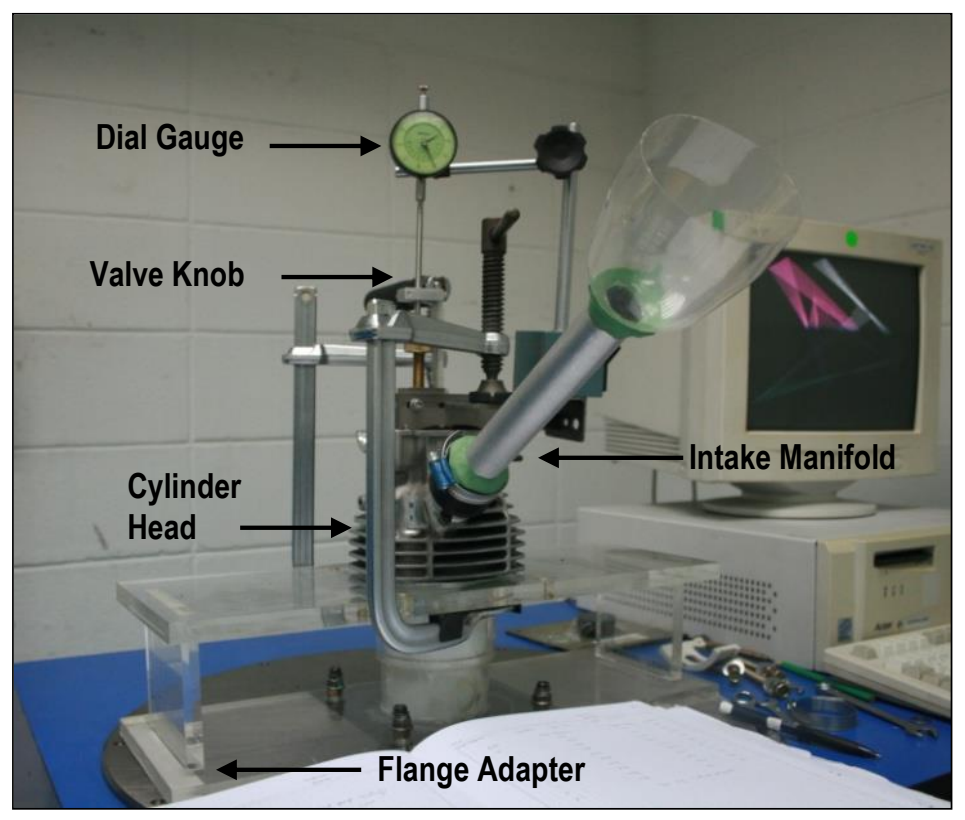

Figure 1: Setting of the flow bench test

Table 1: Specifications of the flow bench system

\begin{tabular}{ll}
\hline \multicolumn{1}{c}{ Parameters } & Value \\
\hline Make and Model & SuperFlow, SF-1020 \\
Flow Measurement Accuracy: & $\pm 0.05 \%$ \\
Flow Repeatability: & $\pm 0.25 \%$ \\
Flow Range: & $12-470 \mathrm{l} / \mathrm{s}$ \\
Pressure Accuracy & $\pm 0.13 \mathrm{~cm}$ of water \\
Pressure Range & $0-165 \mathrm{~cm}$ of water \\
Temperature Accuracy & $\pm 0.3^{\circ} \mathrm{C}$ \\
\hline
\end{tabular}

In the experiments, only the intake valve lift, $L$, was varied, while the exhaust valve remained close at all time. The intake valve was lifted, from a fully closed position, at an increment of one millimeter to a maximum lift of $8.2 \mathrm{~mm}$. The experiments were monitored in term of the ratio of valve lift $(L)$ to valve diameter $(D)$ or $L / D$ ratio. Such a universal ratio is used elsewhere (Ismail et al., 2008) to enable the comparison of parameters such as flow efficiencies regardless of the size of the valve. In each of the experiments, the air flow rate was recorded. In addition, the air temperature was measured to determine the density of air flowing through the intake 
manifold. The pressure difference was set to about $508 \mathrm{~mm}$ water column to ensure negative pressure at the downstream of the flow bench.

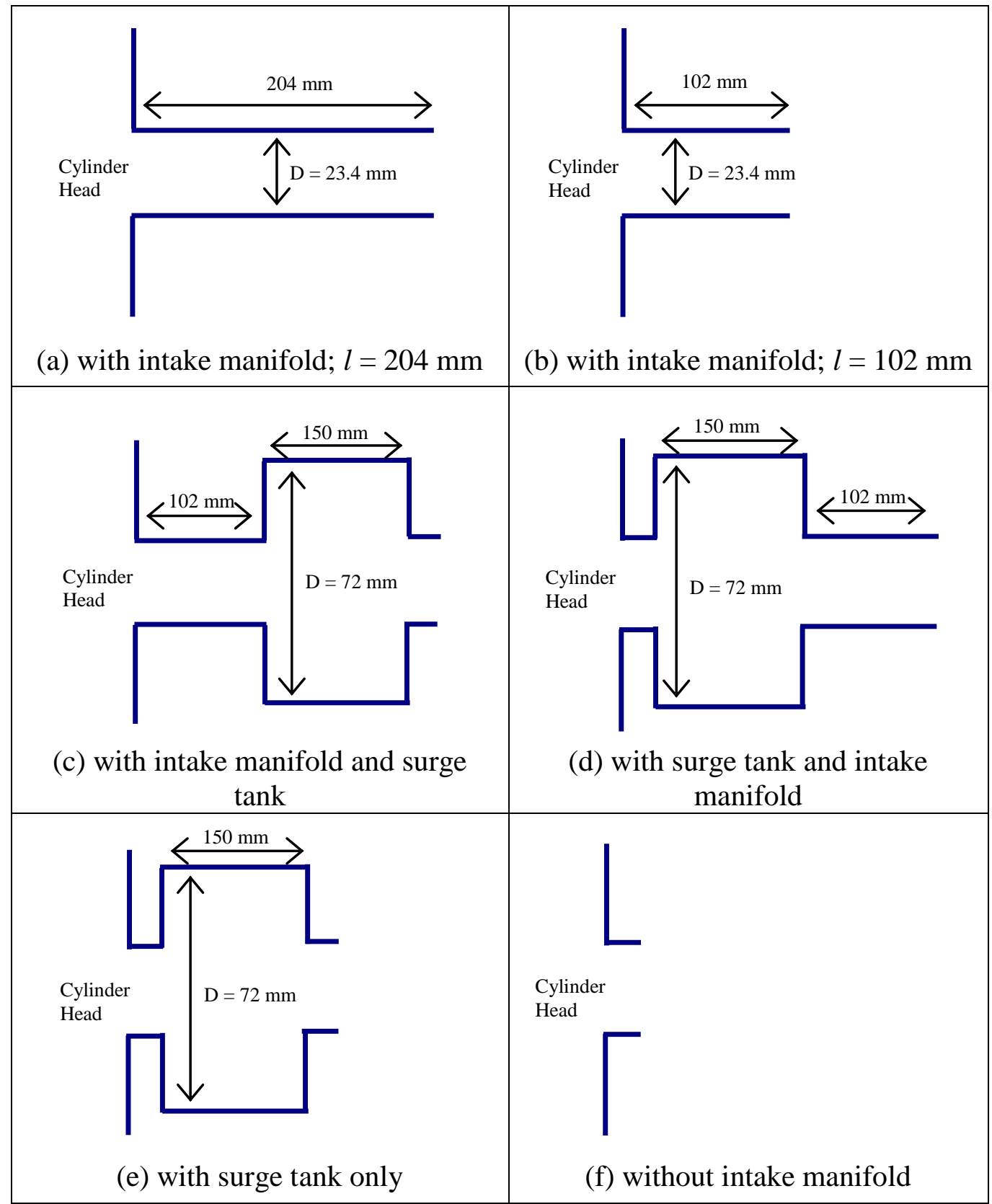

* Not to scale

Figure 2: Variations of the intake manifold configurations for testing with the flow bench

Figure 2 shows the variations of intake manifold configurations tested in the experiments. In Figures 2 (a) and (b), the intake manifolds were straight stainless steel pipes with lengths of $204 \mathrm{~mm}$ and $102 \mathrm{~mm}$, respectively. The internal diameter of the pipe was $23.4 \mathrm{~mm}$ and its thickness was $1.5 \mathrm{~mm}$. The surface roughness was $0.5 \mu \mathrm{m}$. The purpose of having two different pipe lengths was to study the effect of intake manifold length to the air flow. The effect of surge tank within the intake manifold, as shown in Figures 2(c), (d) and (e), was also investigated. The difference between the 
three configurations was only the position of the surge tank. The surge tank was a cylindrical stainless steel chamber with an internal diameter of $72 \mathrm{~mm}$ and length of 150 $\mathrm{mm}$. The reason for conducting the experiments with a surge tank was because it could provide a better air flow rate at higher engine speeds, and thus an increased power at high end RPM during racing. In Figure 2(e), the surge tank was arranged with no pipe. For comparison purpose, a test was also conducted without the use of intake manifold. From the experimental measurements, the flow coefficient of air passing through the intake valve was determined in order to assess its efficiency. The flow coefficient, $C_{D}$ is given by:

$$
C_{D}=\frac{\dot{m}_{a}}{\dot{m}_{t}}
$$

where $\dot{m}_{a}$ and $\dot{m}_{t}$ are the actual and theoretical mass flow rate of air entering the combustion chamber, respectively. The actual mass flow rate is determined experimentally and is given by:

$$
\dot{m}_{a}=Q \frac{P}{R T}
$$

where $Q$ is the volume flow rate, $P$ is the local pressure at the downstream of the intake valve, $R$ is the gas constant of air and $T$ is the local air temperature. The theoretical mass flow rate is calculated by:

$$
\dot{m}_{t}=\rho_{s} A_{k} v_{s}
$$

where $v_{s}$ is the isentropic air density and $A_{k}$ is the valve seat area. The isentropic flow velocity, $v_{s}$, is given by:

$$
v_{s}=\sqrt{\frac{2 \gamma}{\gamma-1} R T\left[1-\left(\frac{P_{2}}{P_{1}}\right)^{\frac{\gamma-1}{\gamma}}\right]}
$$

where $P_{1}$ and $P_{2}$ are the air pressures at the upstream and downstream of the intake valve and $\gamma$ is the index of isentropic expansion.

\section{SIMULATION SETUP}

The intake air manifold system and the combustion chamber were modelled in three dimensions using graphic software, CATIA V5. The model design would resemble the path of air entering the combustion chamber. Shown in Figure 3 is the model of the combustion chamber with the air intake path and valve. The model was meshed with tetrahedral type by using meshing software, Gambit. The meshes were considerably finer $(1,437,285$ mesh volumes) in the combustion chamber where the results of analysis were critical. The flow simulation was performed by using the CFD software, Fluent. The simulations were run based on the Navier-Stokes equations under the $K-\varepsilon$ 
two-equation turbulent model at steady state. The air density was assumed to be constant in the simulation. The Reynolds number was calculated to be 23,765.
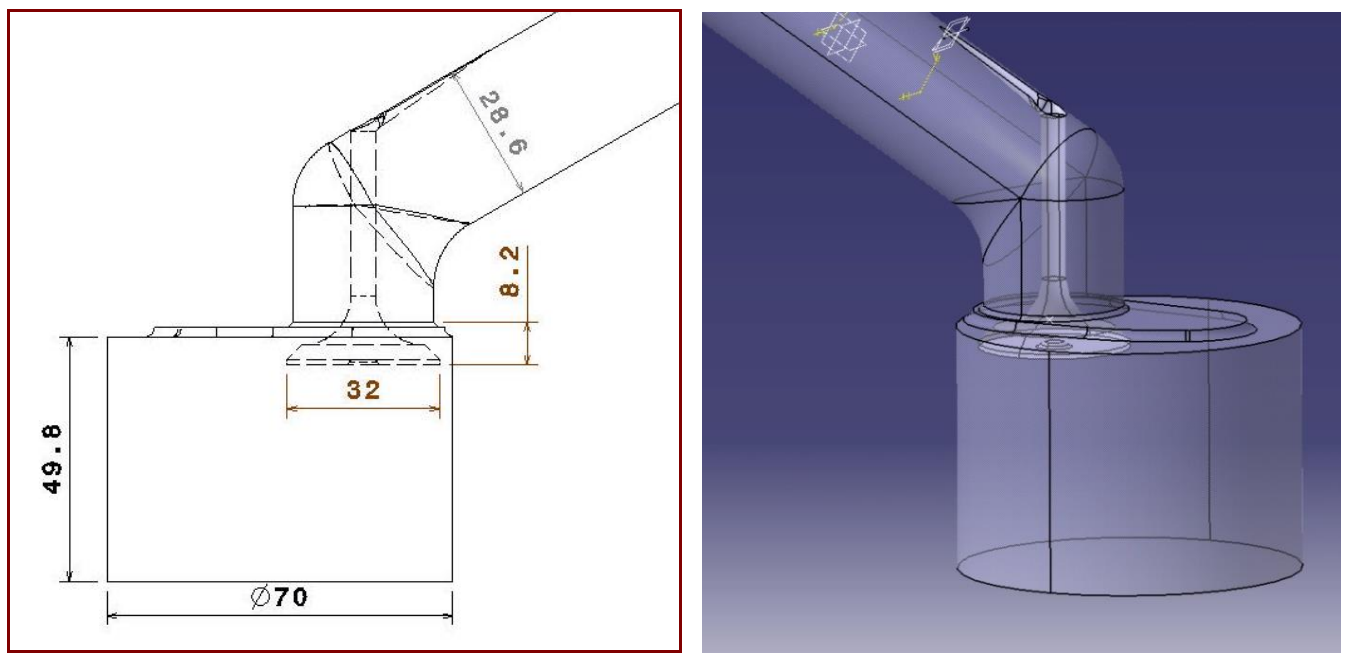

Figure 3: The engine's combustion chamber and air intake valve

The overall view of the modelled system is shown in Figure 4, in which $l$ is the intake manifold length. Shown in Table 2 are the variations and boundary conditions in each of the CFD simulations conducted in the present work. The simulation setting using an intake manifold with a length of $204 \mathrm{~mm}$ is similar to that shown in Figure 2(a), and thus the CFD and experimental results can be compared. Similarly, the setting without intake manifold is similar to that shown in Figure 2(f). The third simulation was conducted using an intake manifold of a different design that resembled a surge tank but with a smooth transition of edge between the tank and the pipe. A bell mouth inlet was incorporated with the intake manifold to smooth the in-flowing air. The design and dimensions of the intake manifold for the third simulation are shown in Figure 5.

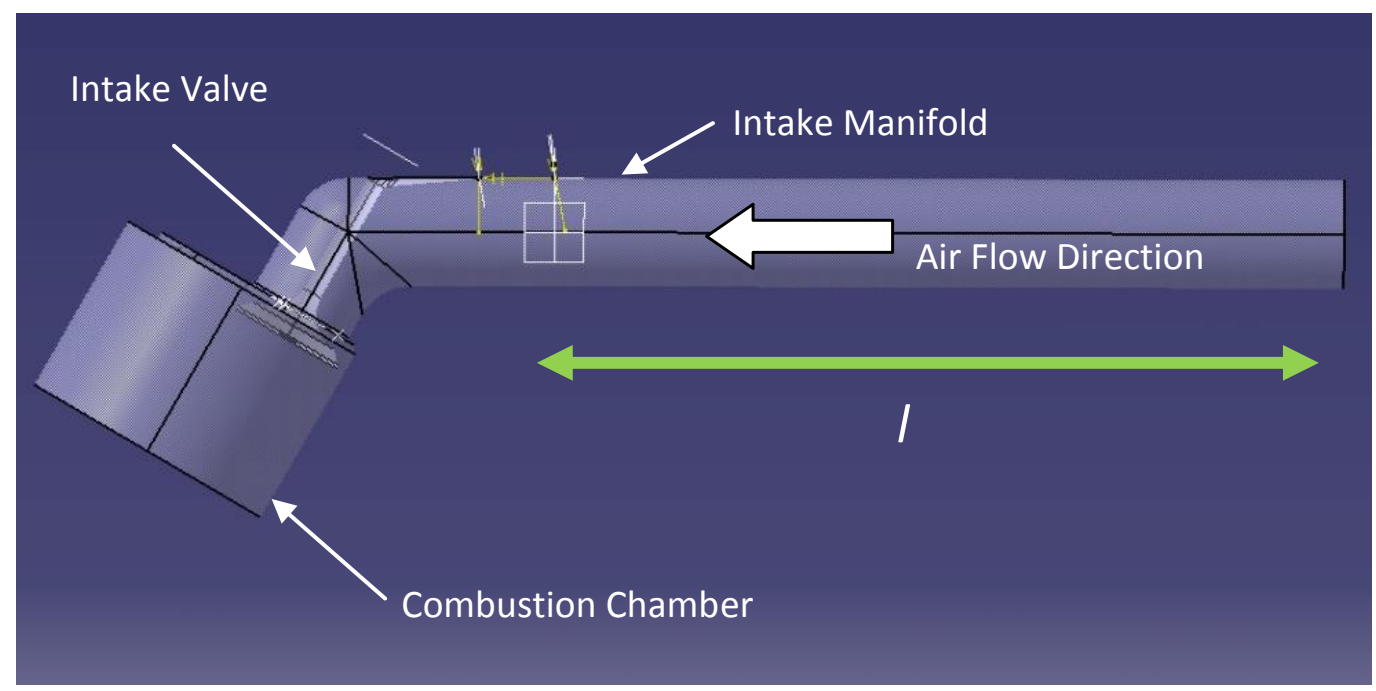

Figure 4: View of the simulated system with an intake manifold length, $l$, of $204 \mathrm{~mm}$ 
Table 2: Intake manifold configurations and boundary conditions

\begin{tabular}{lc}
\hline \multicolumn{1}{c}{ Simulation } & Intake Manifold configuration \\
\hline 1 & With intake manifold; $l=204 \mathrm{~mm}$ \\
2 & Without intake manifold \\
& Surge tank and bell mouth (Figure 5) \\
\hline \multicolumn{1}{c}{ Parameters } & Boundary Conditions \\
\hline Inlet Pressure & Conditions \\
Outlet Pressure & $101.32 \mathrm{kPa}$ \\
\hline \multirow{2}{*}{ Intake Manifold Wall } & $96.08 \mathrm{kPa}$ \\
Roughness & $0.5 \mu \mathrm{m}$ \\
& No Slip Condition \\
Cylinder Head Wall & Stationary Wall \\
Roughness & $25 \mu \mathrm{m}$ \\
& No Slip Condition \\
\hline
\end{tabular}

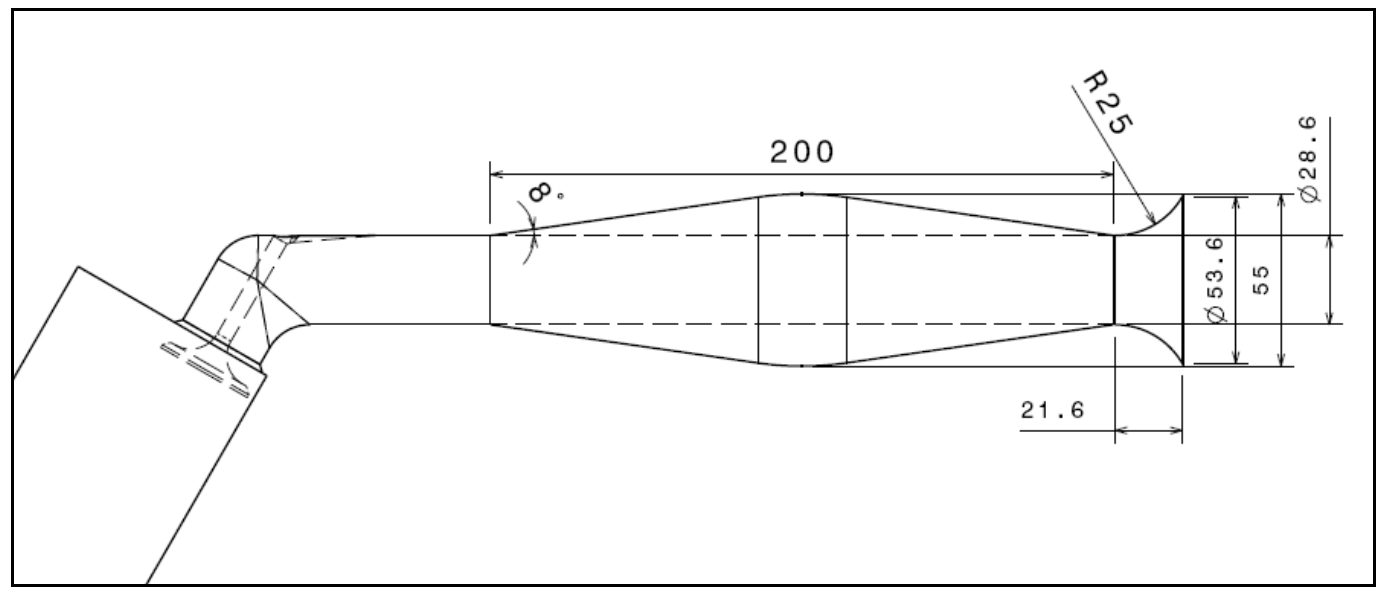

Figure 5: Design of the intake manifold with surge tank and bell-mouth inlet

\section{RESULTS AND DISCUSSION}

\section{Experimental Results}

Shown in Figure 6 is the variation of air flow rate into the combustion chamber with the valve lift, as measured in the experiment. In general, it is seen that the trend of increment of flow rate with valve lift is similar for all test variations. Nevertheless, the rate of change of the flow rate can be divided into three regimes: A, B and C. 


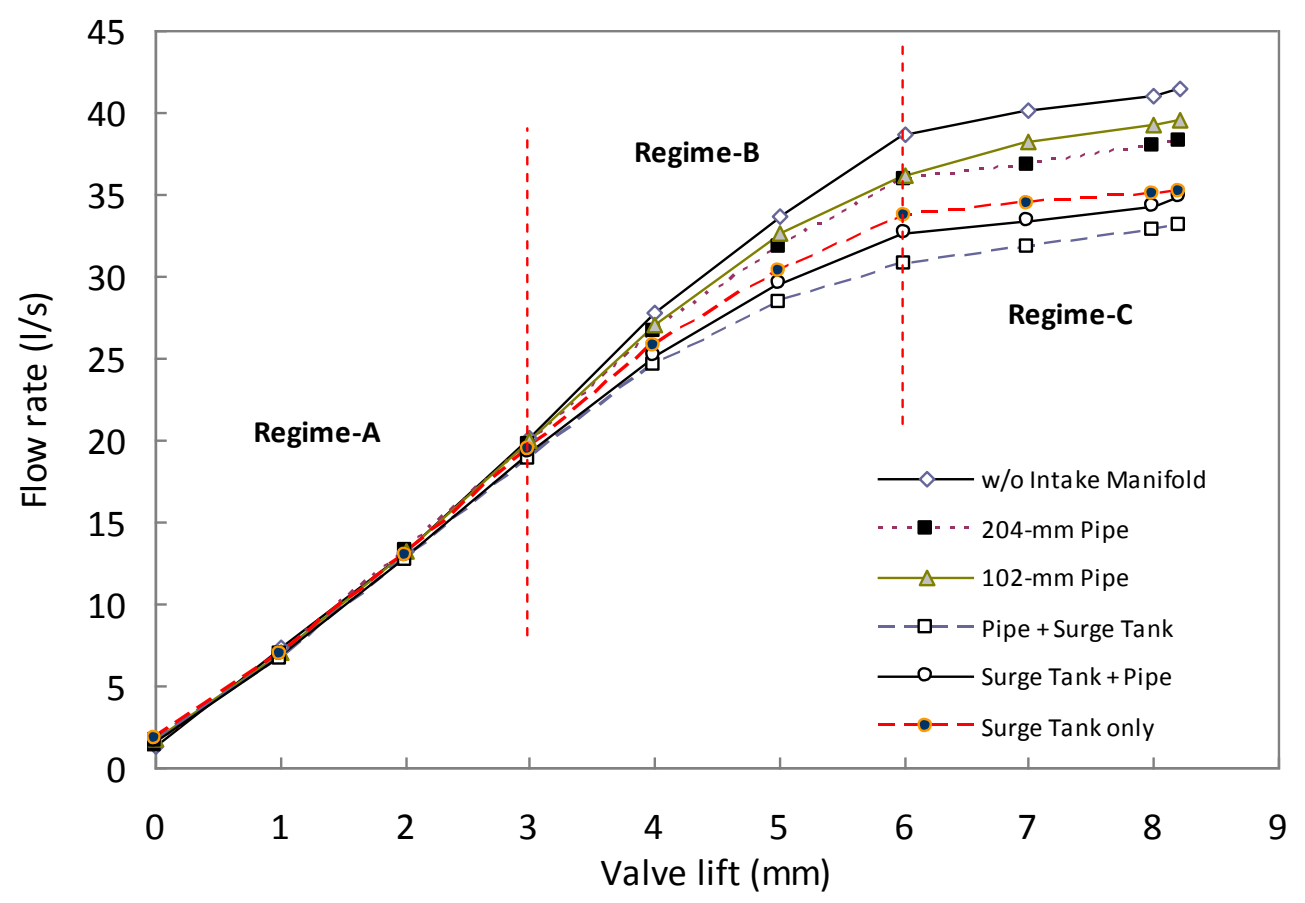

Figure 6: Variation of flow rate of air with the valve lift positions for various designs

In Regime-A, during which the valve lifts are between 0 and $3 \mathrm{~mm}$, the flow rates are seen to be nearly the same for all tests. The largest difference in flow rate within Regime-A is only $1.4 \mathrm{l} / \mathrm{s}$. The small variation within this regime is probably caused by the limited amount of air flowing into the combustion chamber as a result of the small opening of the valve. In other word, the design or configuration of the intake air manifold is shown to have no significant effect on the air flow rate within this regime. The average mass flow rate at $3 \mathrm{~mm}$ valve lift is $19.5 \mathrm{l} / \mathrm{s}$, after which the results are seen to be diverging from each other. The divergence is sustained until a valve lift of $6 \mathrm{~mm}$, and this is identified as Regime-B. When no intake manifold is used it is seen that the mass flow rate is the highest, probably due to reduced flow restriction. Interestingly, the slope for the experiment without intake manifold is seen to be higher in Regime-B than that in Regime-A. This is possibly due to a further reduction of friction loss when the valve lift is higher than $3 \mathrm{~mm}$. Conversely, for other tests in Regime- $\mathrm{B}$, the slopes are seen to be decreasing, probably due to an increase in friction losses within the intake air manifold. With the incorporation of a surge tank, the friction loss is even higher due to the sudden change in diameter, and this causes lower air flow rates. Due to the variation in flow rates, it is suggested that the condition in Regime-B is the most crucial in deciding the design of the intake manifold.

In Regime-C, it is seen that the slopes of the graphs reduce more but are all maintained at nearly the same gradient. Further variation of the intake manifold does not cause any significant change in the air flow rate. It must be noted that although the highest amount of air flow rate into the combustion chamber is experienced when operated without an intake manifold, such a configuration is not possible for the engine due to the need to pre-mix the fuel and air. During the pre-mixing, the fuel is atomized to enhance the power of the engine and to lower the emission rate. 


\section{CFD Simulation Results}

Validations of the CFD simulation results were performed for two settings, which were the engine without intake manifold and with a 204-mm intake manifold. The air intake for these comparisons was set up to a maximum valve lift of $8.2 \mathrm{~mm}$, or wide open throttle. Shown in Figure 7 (a) is the variation of flow coefficient with the ratio of valve lift/diameter $(L / D)$ for the experimental results (from Figure 6) and the CFD results without the intake manifold. It is seen that the trends of results are similar for both the experiment and CFD simulation. The difference between the results is seen to be reasonable. The graph shows a consistent increase in the flow coefficient for the CFD simulation. However, in the experimental results the rate of increase in the flow coefficient is seen to reduce slightly at $\mathrm{L} / \mathrm{D}$ ratios of 0.2 or higher.

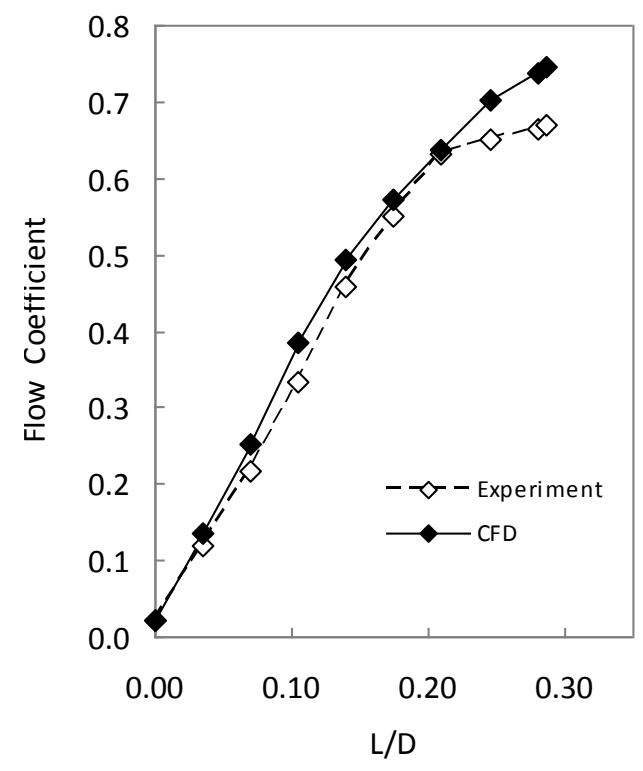

(a) without intake manifold

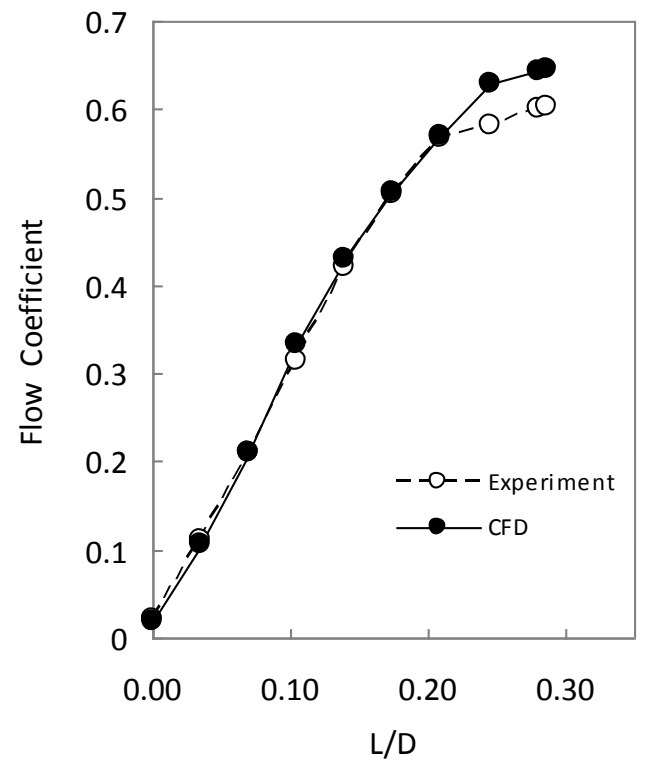

(b) with intake manifold

Figure 7: Variation of flow coefficients with $L / D$

Shown in Figure 7(b) is the variation of the flow coefficient with the ratio $L / D$ for the experimental and CFD results, using a 204-mm length pipe intake manifold. The results in Figure 7(b) are seen to have similar trends to those in Figure 7(a). Likewise, the differences between the experimental and CFD simulation results are reasonable. Thus it is suggested that the CFD software and setting are accurate and thus the simulation results can be used with confidence in decisions related to design of the intake manifold. The consistently higher values of flow coefficient for the CFD simulations than those for the experiments, as shown in Figure 7, are probably due to the simplification of the geometry of the intake port and valve, which results in the model being not exactly the same as the actual system. Furthermore, there could have been various sources of friction losses within the flow bench system that could not be accounted for in the CFD simulation. Sources of friction losses using similar flow bench can be found in the reference (Ismail et al., 2008). Although the flow coefficient in the combustion chamber is important due to its relations to volumetric efficiency, other important aspects should not be neglected. Within the study, the effects of swirl and 
tumble are evidenced in the flows. A comparison was made to qualitatively investigate the effect of different lengths of intake manifold on the resulting swirl and tumble. Shown in Figures 8 and 9 are velocity vector plots of the air flow within the combustion chamber for visualization of tumble and swirl, respectively. The simulations were carried out for straight pipe intake manifolds of different lengths. Comparison of tumbles in Figures 8 (a) and (b) shows that there are more eddies in the combustion chamber when a longer intake manifold is used. In Figure 8 (a), it is also seen that there is a stagnant-like zone (bottom right of image), which is less desirable.

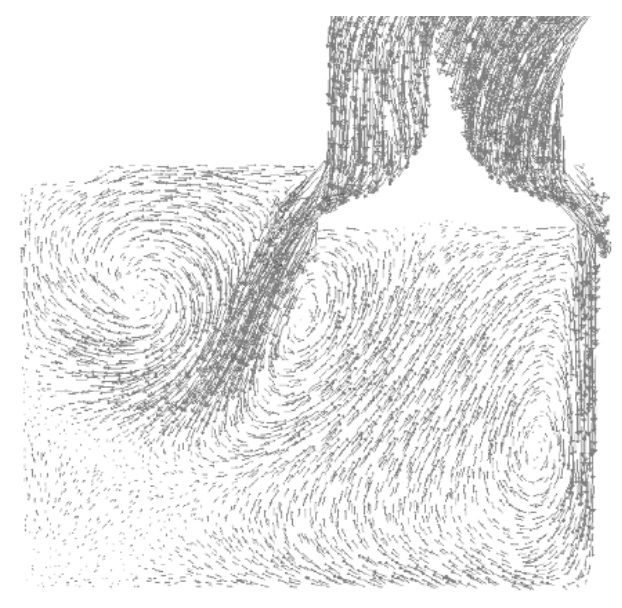

(a) Tumble: $l=200 \mathrm{~mm}$

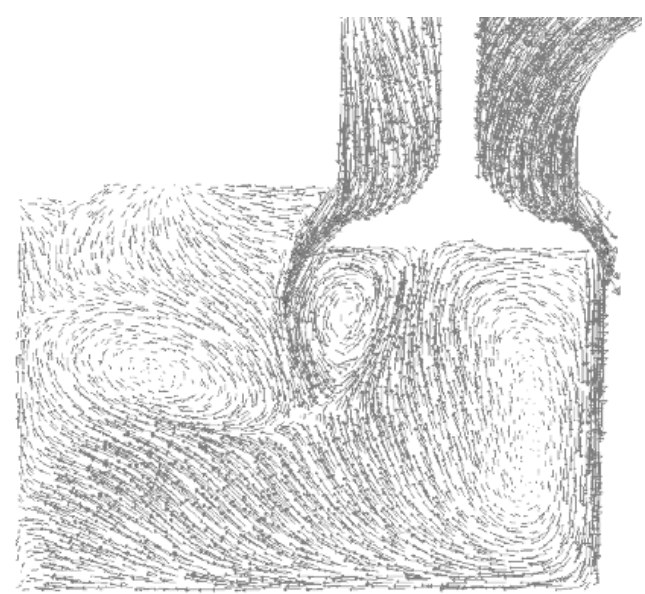

(b) Tumble: $l=230 \mathrm{~mm}$

Figure 8: Typical velocity vector plots for visualization of tumble in the combustion chamber using different lengths of intake manifold

The swirl motions within the combustion chamber are shown in Figures 9 (a) and (b). With the intake manifold length of $200 \mathrm{~mm}$, the swirl motion is seen to be less significant. However, with a longer intake manifold $(l=230 \mathrm{~mm})$, the swirl effect is obvious with the presence of a few large eddies, and hence would lead to enhanced fuelair mixing.

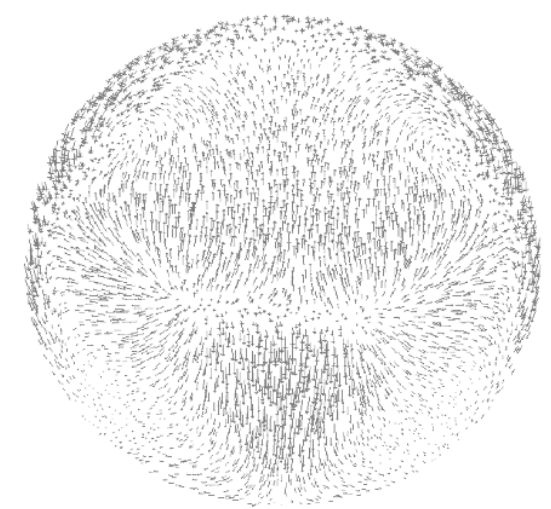

(a) Swirl: $l=200 \mathrm{~mm}$

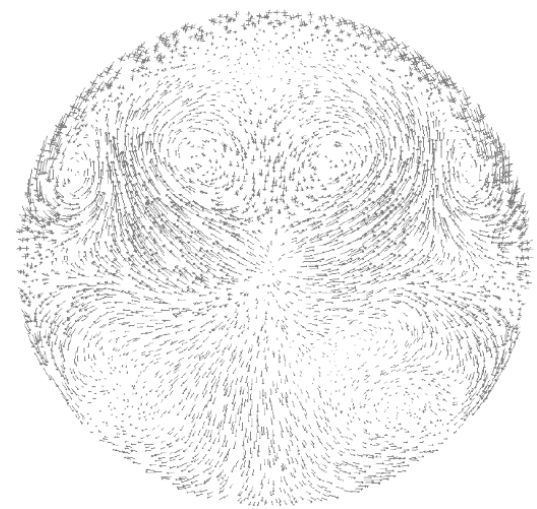

(b) Swirl: $l=230 \mathrm{~mm}$

Figure 9: Typical velocity vector plots for visualization of swirl in the combustion chamber using different lengths of intake manifold 
In general, it is seen from the results in Figures 8 and 9 that a longer intake manifold can increase the effects of tumble and swirl, which are necessary for fuel-air mixing. Nevertheless, it is also shown in the experiment that increasing the intake manifold length will reduce the flow coefficient. Hence, a trade-off between the effects of swirl/tumble and flow coefficient must be considered in the selection of air-intake manifold design.

\section{Investigation of the Boundary Layer Within the Intake Manifold}

The presence of contact surface within the intake manifold is related to friction loss; this also explains the high flow rate of air for the experiment without intake manifold. The fluid particles in the layer in contact with the surface of the pipe come to a complete stop due to the no-slip condition. This layer also causes the fluid particles in the adjacent layers to slow down gradually as a result of friction. To make up for this velocity reduction, the velocity of the fluid at the mid section of the pipe has to increase to keep the mass flow rate through the pipe constant. The region of flow in which the effects of the viscous shearing forces caused by the fluid viscosity are felt is the velocity boundary layer. In the boundary layer, the viscous effects and velocity changes are significant. For the fluid flow in the entrance region of a pipe, the wall shear stress is usually the highest at the pipe inlet where the thickness of the boundary layer is smallest. Therefore the pressure drop is expected to be higher at the entrance region of a pipe.

The hydrodynamic entry length, which is the region from the pipe inlet to the point at which the boundary layer merges at the centerline for the turbulent flow, can be approximated as (Cravalho et al., 2005):

$$
L_{h . t u r b}=1.359 D \operatorname{Re}_{D}^{0.25}
$$

where $D$ is the internal diameter of the pipe and $R e_{D}$ is the Reynolds number. The calculated entry length is found to be $0.533 \mathrm{~m}$ and thus a fully developed air flow cannot be achieved because the intake pipe has only a maximum total length of $0.3 \mathrm{~m}$. The air flow will not be able to develop fully due to insufficient length of pipe. This is also illustrated in Figure 10 by the velocity profiles as determined from the CFD results. It is seen in Figure 10 that the boundary layer of the air flow within is not fully developed. This is due to insufficient length for the velocity profile to become fully developed. The boundary layer may be differently developed for different air intake manifold geometry. In addition, the surface roughness of the intake manifold may determine the pattern of the boundary layer (Merkle et al., 1977). 


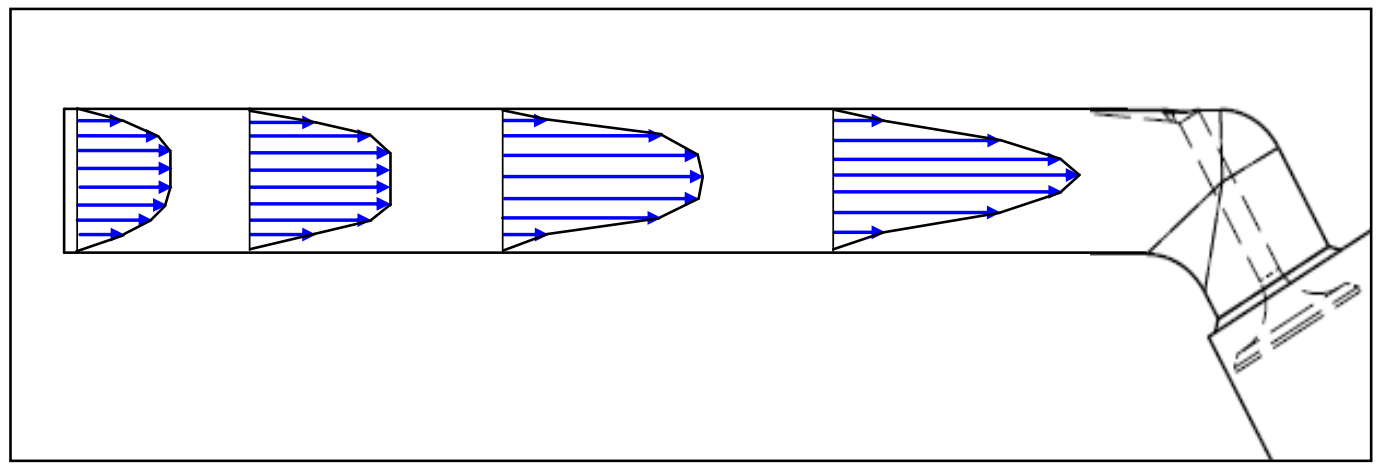

Figure 10: Schematic of the computed velocity profiles in the intake manifold of 204mm length pipe

\section{Simulation of the New Design of Intake Manifold}

Figure 11 shows the variation of flow coefficient obtained from CFD simulation for the new design of intake manifold as depicted in Figure 5. Also shown in the figure are the results for the designs without intake manifold and with the 204-mm pipe for comparison. The simulation conditions for each of the setting were the same. Comparison of the results in Figure 11 shows a slight improvement in the flow coefficient as compared to simulation with a 204-mm intake manifold particularly at $L / D$ ratios of greater than 0.10 . Nevertheless, the flow coefficient for the system without intake manifold is seen to be the highest, as earlier elaborated for Figure 6. Thus, it is proposed that the new design has the potential of increasing the flow coefficient and volumetric efficiency, particularly if the carbureted system were to be replaced by a fuel injection system within the intake manifold.

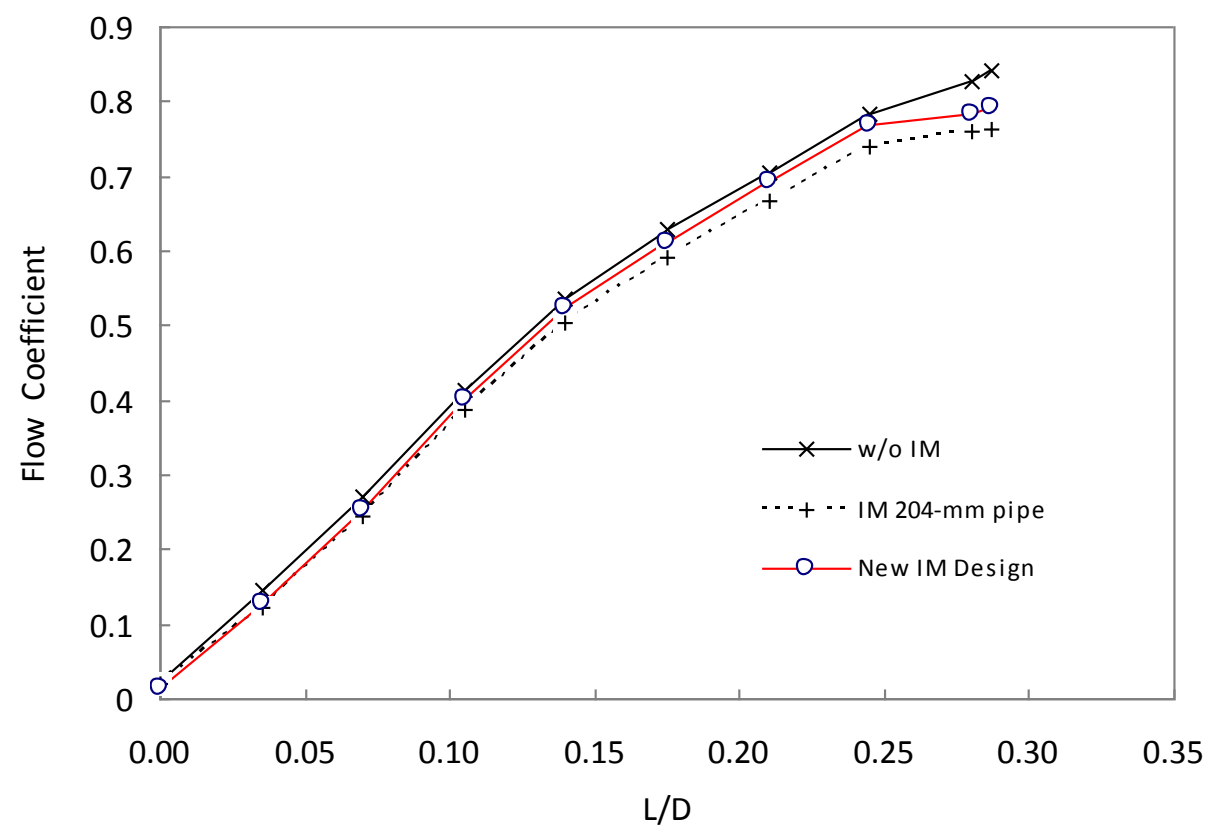

Figure 11: Variation of simulated flow coefficients with $L / D$ for various intake manifold designs 


\section{CONCLUSIONS}

The present work shows that the flow of air through the intake valve, as a result of various intake manifold configurations, can be divided in three regimes. At small valve lifts ( 0 to $3 \mathrm{~mm}$ ), the flow rates are indifferent to the intake manifold. Within the second regime, when the valve lifts are between 3 and $6 \mathrm{~mm}$, the flow rates of air within the intake valve differ individually depending on the configuration or design of the intake manifold. It is suggested that the behaviour of flow in this regime be used as one of the main considerations in choosing a manifold design. Although it is seen that the highest amount of air flow rate into the chamber is experienced when operated without the intake manifold, it is not possible for the engine to have such a configuration due to the need to pre-mix the fuel and air and to atomize the liquid fuel; unless a direct injection system is adopted. Despite the good effects of swirl and tumble demonstrated by the use of long intake air manifold in the CFD simulation, it is seen from the experiment that long manifolds would result in a drop in the flow coefficient. Thus a trade off between the effects of swirl and tumble and good flow coefficient must be studied in choosing the best intake manifold configuration.

Comparisons between the experimental and simulation results with two intake manifold configurations show reasonably good agreement, thus suggesting the reliability of the simulation in demonstrating the effects of valve lifts and intake manifold configurations. From the simulation work it is seen that the flow in the intake manifold can never become fully developed due to the short pipe length, and this may probably affect the flow coefficient. In the simulation using a new design of intake manifold, which had a surge tank with tapered edges and bell mouth inlet, the flow coefficient is shown to be improved by up to $6 \%$ and is found to be better than the existing carbureted system (actual data belongs to the undisclosed manufacturer and is therefore confidential). This implies that the new design is capable of increasing the volumetric efficiency, and should be considered if the present carbureted system were to be replaced by a fuel injection system.

\section{ACKNOWLEDGEMENTS}

The authors would like to acknowledge the support of Universiti Teknologi PETRONAS in the present work.

\section{REFERENCES}

Cravalho, E.G., Smith, J.L., Brisson, J.G. and McKinley, G.H. (2005) An Integrated Approach to Thermodynamics, Fluid Mechanics and Heat Transfer. Cambridge, MA: Oxford University Press.

Fontana, G., Galloni, E., Jannelli, E. and Palmaccio, R. (2003) Influence of the Intake System Design on a Small Spark-Ignition Engine Performance: A Theoretical Analysis. SAE Paper No. 2003-1-3134.

Ismail, A.R., Bakar, R.A. and Semin (2008) An Investigation of Valve Lift Effect on Air Flow and CD of Four Stroke Engines Based on Experiment. American Journal of Applied Sciences, 5: 963-971.

James, O. D. 2004. Gokartracer. August 2008, www.gokartracer.com. 
McLandress, A., Emerson, R., McDowell, P. and Rutland, C.J. (1996) Intake and InCylinder Flow Modeling: Characterization of Mixing and Comparison With Flow Bench Results. SAE Transactions, 105: 868-881.

Merkle, C.L., Tzou, K.T.S. and Kubota, T. (1977) An Analytical Study of The Effect of Surface Roughness on Boundary-Layer Stability. Technical Report, Defense Technical Information Center.

Pulkrabek, W.W. (2004) Engineering Fundamentals of the Internal Combustion Engine. New Jersey: Prentice Hall.

Srinivasan, S. (2001) Automotive Engines. New Delhi: Tata McGraw-Hill.

Winterbone, D.E. and Pearson, R.J. (1999) Design Techniques for Engine Manifolds: Wave Action Methods for IC Engines. USA: Society of Automotive Engineers. 